\title{
Methodology for FTIR Imaging of Individual Cells
}

\author{
Seydou YaO $^{a}$, M. Cestelli Guidi ${ }^{b}$, M. Delugin ${ }^{c}$, G. Della-Ventura ${ }^{d}$, \\ A. MARCElli ${ }^{b, e}$ AND C. Petibois ${ }^{c, *}$ \\ ${ }^{a}$ Centre for NanoHealth, Institute of Life Science 2 Building, Swansea University, \\ Singleton Park, Swansea, Abertawe, SA2 8PP, UK \\ ${ }^{b}$ INFN, Laboratori Nazionali di Frascati, Via E. Fermi 40, I-00044 Frascati (Rome), Italy \\ ${ }^{c}$ Université de Bordeaux; Inserm U1029 LAMC, Allée Geoffroy Saint-Hillaire, Bat B2, 33600 Pessac, France \\ ${ }^{d}$ Dipartimento Scienze Geologiche, Università Roma Tre, Roma, Italy \\ ${ }^{e}$ RICMASS, Rome International Center for Materials Science Superstripes, 00185 Rome, Italy
}

\begin{abstract}
FTIR imaging is a novel spectroscopic technique able to provide cell imaging, in vivo and in real-time. However, one key issue is developing methodologies for cell culture on IR-transparent substrates fitting cell biology requirements. In this work we tested different IR-transparent substrates in terms of biotoxicity, surface properties, and spectral image acquisition qualities. Only a few substrates, namely $\mathrm{Si}_{3} \mathrm{~N}_{4}, \mathrm{Ge}, \mathrm{GLS}, \mathrm{LaF}_{3}, \mathrm{Si}, \mathrm{SrF}_{2}$, $\mathrm{ZnS} / \mathrm{C}, \mathrm{ZnS} / \mathrm{F}$, were found to provide cell culture conditions comparable to those observed on usual polycarbonate Petri dishes, the main limiting parameter being the toxicity of the material $\left(\mathrm{ZnS}, \mathrm{GLS}, \mathrm{PbF}_{2}, \mathrm{PbCl}_{2}\right)$ or a poor adhesiveness (notably diamond, $\mathrm{AgCl}, \mathrm{CaF}_{2}, \mathrm{ZnS}$ ). From substrates eligible for a good-quality cell culture, the spectral acquisition quality is mainly affected by the refractive index value. Finally, the best compromise between cell culture quality and image spectral quality could be obtained using Si and Ge substrates. This rationalization of the available IR-transparent substrates for bioimaging is particularly relevant for live cell analyses, where cell culture conditions must remain unaffected by substrate properties.
\end{abstract}

DOI: 10.12693 /APhysPolA.129.250

PACS: 82.80.--d, 87.85.Pq, 87.64.--t

\section{Introduction}

In the field of cell imaging, there are two main kinds of techniques: 1 - those based on contrast agents or probes for analyzing a selected cellular compound, such as UVconfocal microscopy; and 2 - those based on bulk information of sample, as for spectroscopy-based techniques, such as the Raman or FTIR [1, 2]. The clear advantage of probe-based techniques is to define a priori and without doubt the cellular information to analyze, thus giving access to very precise information, quantitative as well as topographic, when $3 \mathrm{D}$ rendering is feasible [3]. Bulk analytical methods usually are not accurate, but by opening the spectrum of information collected from the sample, they also allow access to many characters relating to cell contents [4]. Another major difference between these two aspects of cell imaging is that by focusing on a single target in the confined environment of a cell, probe-based techniques have to be developed for very fast acquisitions (real-time at the ms scale and below), and at spatial resolution down to the nanoscale [5]. This is clearly an analytical challenge that spectroscopic analytical methods will have to face up to continue playing a role in the field of cell imaging.

Among the available techniques, the Raman microscopy seems to have gained in visibility by reaching $\approx 250 \mathrm{~nm}$ spatial resolution for the semiconfocal se-

\footnotetext{
* corresponding author; e-mail:
} cyril.petibois@u-bordeaux.fr tups [6], a value satisfactory for imaging many cell subcompartments, such as mitochondria, vesicles, and the nucleus. It can be also coupled to other techniques, such as atomic force microscopy (AFM) or UV fluorescence, allowing a multimodal analysis of samples [1]. However, live cell imaging is not a viable routine while using the Raman microscopy, due to ionization and heating effect on cells and also because of the long acquisition required by a $3 \mathrm{D}$ mapping ( $\approx 1 \mathrm{~h}$ for high quality spectral acquisition) [7]. Among drawbacks, the laser effect on cell seems the most limiting parameter for cell imaging studies, since no cell biochemical processes can be investigated under a laser irradiation [8, 9]. This laser effect can be moderated thanks to heat dispersion by water. To the contrary, FTIR imaging is now routinely used for analyzing biosamples, notably tissue sections [10]. It is however still in an experimental development phase for a routine use for cell imaging $[1,11,12]$, suffering principally from the lack of spatial lateral resolution, typically a few $\mu \mathrm{m}$, which is not sufficient for sub-cellular analyses.

Traditionally, FTIR imaging is used in transmission, reflectance or transflectance mode with some major limits [13], such as dispersion artifacts (i.e., the Mie scattering), a lateral resolution diffraction limited as a function of wavelength $(\lambda / 2$ at the best: $3-6 \mu \mathrm{m}$ in the mid-IR spectral interval), the impossibility to analyze living samples due to water absorption fluctuations, and a limited sensitivity while analyzing very small samples, namely single cells [12]. Synchrotron radiation [14] may overcome these drawbacks thanks to the enhanced signal-tonoise ratio (SNR) while using a focal-plane array (FPA) detector, within short-time acquisitions (1-2 min). In 
vitro imaging has been also shown to work with globar and SR sources, thus promising routine and high spectral quality results, respectively [15]. To benefit from SR source performances, a specific experimental setup was proposed, where the IR beam was tuned in such a way to maximize the photon flux homogeneity between pixels rather than an intense small photon spot [11]. This was a real advancement if compared with previous image acquisition based on single element detector, that requires long acquisition time affected also by beam stability and homogeneity of SNR [16]. However, recent technological developments on FTIR imaging systems are now allowing the use of attenuated total reflection (ATR) crystals coupled to FPA detectors [15]. This clearly opens new frontiers to live cell imaging and even real-time analyses if we use a SR-IR beam [8] for reducing the acquisition time down to to the second and subsecond domain [9]. The expected analytical performances of this new ATR-FTIR imaging setup include a lateral resolution of $1 \times 1 \mu \mathrm{m}^{2}$ or below, collecting the evanescent signal on the crystal surface for in vitro measurements with a negligible contribution by water absorptions.

However, this setup requires that the cell culture is performed directly on the ATR crystal, usually made by germanium (Ge) or diamond (Dd) crystals for the existing contact-mode devices. At present, no systematic studies are available on the most used IR-transparent windows to determine which substrate can match the quality of cell culture performed on a polycarbonate Petri dish. Recently, an interesting study has compared seven IR slides $\left(\mathrm{CaF}_{2}, \mathrm{Si}, \mathrm{ZnSe}, \mathrm{BaF}_{2}, \mathrm{ZnS}\right.$, MirrIR, $\left.\mathrm{Al}\right)$, which are the mostly used for FTIR microscopy of cells, but did not tested their biotoxicity level and other substrates were not considered [17]. This is a major methodological issue for developing live cell imaging using an ATR crystal supports for proposing new protocols for biological researches. Here, we present a cell culture study on 15 IR-transparent windows to determine which substrates offer the best compromise between cell culture quality expectations and IR spectral image quality. The study focuses both on cell growth parameters (biotoxicity, division, differentiation... ) and spectral information quality (spectral information obtained at nucleus, cytosol, and membrane locations) extracted from FTIR images of individual cells.

\section{Materials and methods}

\subsection{IR-transparent substrates}

The 15 substrates selected for this study are listed in Table I with their main optical properties (most of optical properties are available at www.crystran.co.uk/). Polycarbonate and glass have been added for biotoxicity and adhesion values, thus allowing a direct comparison with results on IR-transparent substrates.

\subsection{Cell culture}

A dedicated cell culture method has been set up to allow a molecular analysis by FTIR imaging. The cell line used to test the culture method was the U87 human glioma cells (ATCC, HTB-14), which is highly proliferative and well resistant to stress factors. Cells were grown in a DMEM/F-12 medium supplemented with $10 \%$ fetal calf serum, $1 \mathrm{~g} / \mathrm{L}$ of glucose, glutamine and antibiotics. Cells were routinely propagated in a humidified $5 \%$ $\mathrm{CO}_{2}$ atmosphere at $37^{\circ} \mathrm{C}$ (Heraeus incubator BB-6060). For obtaining a majority of individual cells on the IRtransparent substrate, sub-confluent cells were washed with PBS and incubated for $18 \mathrm{~h}$ in DMEM F405-derived serum-free medium containing $5.55 \mathrm{mmol} / \mathrm{L}$ glucose.
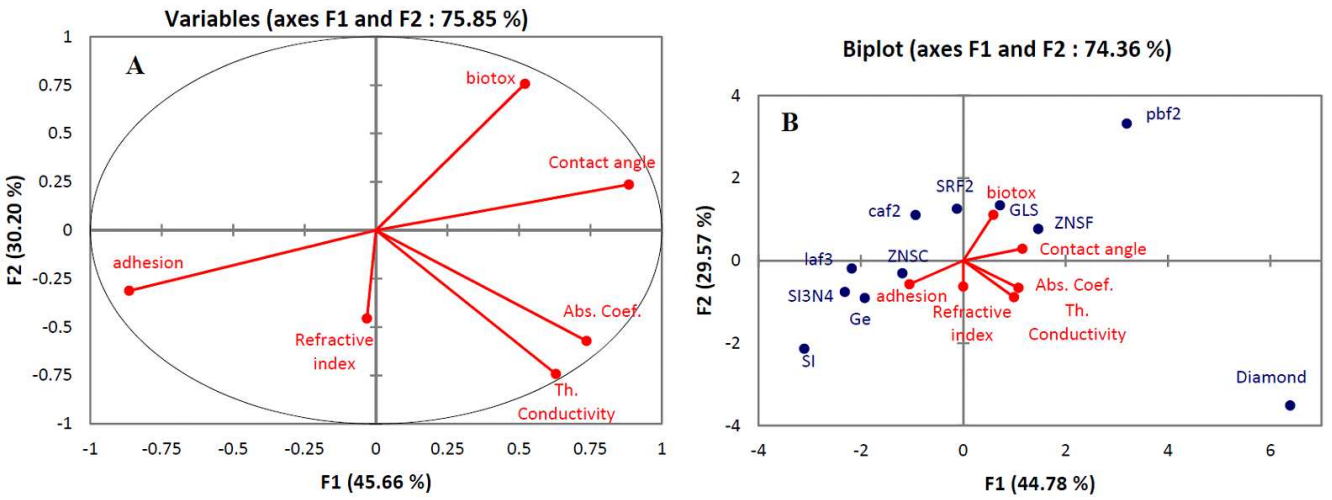

Fig. 1. Principal component regression. A) The ellipse shows the correlation between different parameters and the factors F1, F2. B) Biplot of parameters and substrates positions vs. the factor F1 and F2.

Cell cultures on IR-transparent windows were performed in parallel after sterilization of supports $(24 \mathrm{~h}$ bath in ethanol + UV radiation for $15 \mathrm{~min}$ ). Supports were placed in the Petri dishes before inserting culture medium and cells. Cells were incubated for $24 \mathrm{~h}$ before removing the substrates and washed three times with PBS. Residual buffer was removed by contact of substrate corner with absorbent paper. Substrates were immediately 
placed into tubes, closed and plunged in liquid $\mathrm{N}_{2}$ for cryofixation. Tubes were further placed into a dry chamber with laminar flux at $-20^{\circ} \mathrm{C}$ and open for slow lyophylization $(12 \mathrm{~h})$ to remove cellular water. After closing the tubes to avoid moisture deposition at temperature changes, samples were removed from the chamber and tubes could be open again after return to ambient temperature and substrates could be removed. Cell counting on substrate and the Petri dish (both on the same well and on control wells) was performed optically under an optical microscope for 3 different $2 \times 2 \mathrm{~mm}^{2}$ areas on every substrate. Examples of cell cultures performed on different IR-transparent substrates are shown in Fig. 1.

\subsection{FTIR imaging}

Optical and FTIR images were performed with the same microscope (Bruker Hyperion 3000 with a $64 \times 64$ elements FPA detector) coupled to a FTIR spectrometer (Bruker Equinox 55) illuminated by a synchrotron radiation IR source $(\varnothing \approx 35 \mu \mathrm{m})$ as described elsewhere [18]. $\mathrm{N}_{2}$ purge was performed on both the microscope and the spectrometer for ensuring optimal spectra acquisitions and the plexiglass box (on the front of IR microscope) filled for better $\mathrm{N}_{2}$ purge effectiveness. FTIR spectra acquisitions were performed in transmission mode, using 128 co-added scans $\left(4000-900 \mathrm{~cm}^{-1}\right)$ and a $8 \mathrm{~cm}^{-1}$ spectral resolution. Individual cells were analyzed in triplicate per window with the magnification level sets at $36 \times$ (the final IR image has a pixel size of about $\left.\approx 1.1 \times 1.1 \mu \mathrm{m}^{2}\right)$. From each 2D image, the spectrum with higher signal level at amide spectral interval corresponding to the nucleus location was extracted. Then the integration of absorption from lipids $\left(3000-2850 \mathrm{~cm}^{-1}\right)$, amides I (1720-1600 $\left.\mathrm{cm}^{-1}\right)$ and II $\left(1600-1490 \mathrm{~cm}^{-1}\right)$ bands were performed.

\subsection{Statistics}

The first analysis between cell culture and substrate properties was the evaluation of biotoxicity and adhesiveness. All substrates identified as unsuitable for cell culture were removed from the further analysis. Significant parameters of a substrate were identified and evaluated. The first step was discriminating the covariables of substrates, i.e., potential redundancy of variables evaluating the same substrate of the cell culture parameter. The correlation test has been made for the main substrates properties (see supplementary material — Table I). A correlation matrix was built among optical properties of substrates and SNR values at different spectral intervals using the Pearson coefficient with a limit of confidence set at $5 \%$. Multivariate analysis of the correlation among optical and spectral data was also performed using principal component regression (PCR).

\section{Results and discussion}

The aim of this study was to determine an optimized substrate characterized by the most suitable properties for FTIR imaging of cells directly grown on this support. The objective is a critical step before proceeding to develop dedicated methodologies for live cell imaging by FTIR spectro-microscopy [9]. Actually, we look for a substrate characterized by optimal optical properties, allowing simultaneously cell culture in conditions better or comparable to the routine cell biology procedures, where polycarbonate (PC) or glass-made Petri dishes are used. The most relevant parameter for cell biology is the biocompatibility of the substrate, which can be characterized both by cell viability and by cell adhesiveness on the surface (Table II). Considering biotoxicity, we may point out that $\mathrm{Ge}$, $\mathrm{Si}$, diamond, $\mathrm{Si}_{3} \mathrm{~N}_{4}$, and $\mathrm{LaF}_{3}$ are the only substrates offering comparable biocompatibility (less than $10 \%$ cell death) to PC (5\% cell death) or glass (3\% cell death). The ZNS/C was also very close with a value of $\approx 11 \%$ of cell death. Thus, the first useful information of this study is that the widely used substrates for FTIR spectroscopy and imaging in biosciences, i.e., $\mathrm{CaF}_{2}, \mathrm{ZnSe}$, and $\mathrm{ZNS} / \mathrm{F}$, are too toxic to allow a normal cell culture. It is thus obvious that substrate effects induced on cells can alter and even overcome effects induced by drugs, radiations... etc. masking the "real" experimental results. This critical issue points out the urgent need to define dedicated protocols for IR imaging techniques applied to live cell studies. The second parameter we took into account is cell adhesiveness on substrates. Compared to PC $\left(187 \mathrm{cell} / \mathrm{mm}^{2}\right)$ or glass $(171$ cells $\left./ \mathrm{mm}^{2}\right)$, IR-transparent substrates providing satisfying results were $\mathrm{Si}_{3} \mathrm{~N}_{4}>\mathrm{Si}>\mathrm{LaF}_{3}>\mathrm{ZNS} / \mathrm{C}>$ Ge. All other substrates clearly show much lower cell adhesiveness. Again, $\mathrm{CaF}_{2}, \mathrm{ZnSe}$, and $\mathrm{ZNS} / \mathrm{F}$ substrates are not satisfying in term of cell culture parameters, ruling out definitively such IR-transparent supports for IR imaging applications of cultured cells. A particular case is diamond that although shows a low toxicity exhibits also one of the lowest adhesiveness. Indeed, before removing the support from the Petri dish, optical observations showed on the diamond surface a large number of living but floating cells or cells grown only on surrounding PC or glass surface of the Petri dish. This is certainly due to the surface properties of the diamond, which is characterized by very few hydroxyle residues [19]. The latter are necessary to cells to covalently bind ECM components (polysaccharides and fibrous proteins). Diamond is a good example of substrate with a low toxicity for cell culture but also physical properties inhibiting the cell adhesion on its surface. It cannot be considered suitable for cell cultures. To conclude about biocompatibility, the best substrates are $\mathrm{Si}_{3} \mathrm{~N}_{4}, \mathrm{Si}, \mathrm{LaF}_{3}$, and Ge. It must be stressed here that, except Ge, regularly used for reflection measurements in the mid-IR region due to its high refractive index $(4.0)$ compared to biosamples $(\approx 1.2-1.4)$, the other biocompatible substrates are rarely used by spectroscopists [11, 20-25].

As a second step, we analyzed FTIR imaging data obtained on cryofixed cells grown on the substrates considered suitable. In particular, we checked about corre- 
lations between physical characteristics of the substrate and absorptions of amides and lipids [26] at nucleus location. Because of their weak absorptions at the single cell level, saccharides and phosphates were not considered in this study. The aim was to define which substrates may provide the highest SNR on FTIR image spectra of a cell. Obtaining high SNR level is critical for imaging applica- tions because cryofixed cells contain a very low amount of organic materials which is reflected by a really small intensity at the pixel level. Considering a lateral resolution of $1.1 \times 1.1 \mu \mathrm{m}^{2}$, it can be estimated that each pixel receives photons originated by an interaction with an amount of organic matter from 0.01 to $0.15 \mathrm{ng}$ located from cytosol to nucleus locations.

TABLE I

Main optical properties of IR-transparent substrates. $n=$ refractive index, $R=$ reflection coefficient; $T=$ transmission coefficient; $A=$ absorption transmission coefficient; $k=$ thermal conductivity; $\varepsilon=$ dielectric constant; $\tau=$ contact angle; $b=$ biotoxicity; $a=$ adhesion; n.a. $=$ not accessible. Units: $n[10 \mu \mathrm{m}] ; A\left[\mathrm{~cm}^{-1}\right]$ at $10 \mu \mathrm{m} ; k\left[\mathrm{~W} \mathrm{~m}^{-1} \mathrm{~K}^{-1}\right]$ at $293 \mathrm{~K} ; \varepsilon[\mathrm{GHz}]$ at $300 \mathrm{~K}$; $\tau$ [deg.]; $b$ [\% of cell death]; $a$ [cells cm$\left.{ }^{-1}\right]$ - after $24 \mathrm{~h}$ incubation.

\begin{tabular}{c|c|c|c|c|c|c|c|c|c|c|c|c|c|c|c}
\hline \hline & $\mathrm{PC}$ & glass & $\mathrm{Ge}$ & $\mathrm{SrF}_{2}$ & $\mathrm{LaF}_{3}$ & $\mathrm{ZNS} / \mathrm{C}$ & $\mathrm{ZNS} / \mathrm{F}$ & $\mathrm{GLS}$ & $\mathrm{Si}_{3} \mathrm{~N}_{4}$ & $\mathrm{Si}$ & $\mathrm{CaF}_{2}$ & $\mathrm{ZnSe}$ & $\mathrm{D}$ & $\mathrm{AgCl}$ & $\mathrm{PbF}$ \\
\hline$n$ & - & - & 4.01 & 1.39 & 1.60 & 2.49 & 2.24 & 2.40 & 1.98 & 3.42 & 1.39 & 2.43 & 2.38 & 1.99 & 1.70 \\
$R$ & - & - & 0.36 & 0.03 & 0.05 & 0.18 & 0.15 & 0.29 & 0.11 & 0.30 & 0.03 & 0.17 & 0.17 & 0.11 & 0.07 \\
$T$ & - & - & 1.88 & 1.32 & 1.44 & 1.72 & 1.67 & 1.70 & 1.59 & 1.84 & 1.32 & 1.71 & 1.70 & 1.60 & 1.48 \\
$A$ & - & - & 0.027 & 0.001 & 0.00085 & 0.0006 & 0.02 & 0.005 & 0.005 & 0.00001 & 0.0078 & 0.0005 & 0.07 & n.a. & 0.018 \\
$k$ & - & - & 58.61 & 1.42 & 5.1 & 27.2 & 16.7 & 0.43 & 30 & 163.3 & 9.71 & 19 & 2600 & 1.15 & n.a. \\
$\varepsilon$ & - & - & 16.09 & 1.93 & 2.56 & 6.22 & 5.02 & 5.75 & 3.93 & 11.70 & 1.92 & 5.88 & 5.67 & 3.98 & 2.88 \\
$\tau$ & - & - & 38.32 & 74.24 & 64.29 & 70.81 & 78.62 & 71.08 & 60.41 & 45.58 & 50.76 & 70.36 & 94.92 & 73.20 & 93.60 \\
$b$ & 5 & 3 & 2 & 16 & 7 & 11 & 23 & 31 & 6 & 3 & 19 & 29 & 5 & 33 & 61 \\
$a$ & 187 & 171 & 107 & 44 & 155 & 109 & 9 & 7 & 164 & 157 & 24 & 17 & 5 & 9 & 4
\end{tabular}

The substrate physical characteristics are described as a matrix of covariables (Table I). Coming directly from the electrodynamics, several quantities were found strictly related: refractive index, dielectric constant, reflection coefficient, and transmission coefficient. Therefore, a significant correlation was obtained and three of these parameters could be removed from the study because of their redundancy, maintaining only the refractive index. Table II shows the bilateral correlation values between substrates optical parameters and IR spectral data at the nucleus location. Except the negative relationship found between the IR absorption level of the amide contribution and the contact angle of substrates, no other correlation emerges. The negative correlation found between the IR absorption level and the contact angle is however, an additional demonstration that the cell adhesiveness is a prerequisite for a valuable live cell imaging protocol. The opposite behavior observed between cell adhesion and contact angle in the correlation plot of the Fig. 1A points out the role of substrates physical property to obtain a standard cell growth. However, the lack of positive correlation with any other physical parameter demonstrates that no individual parameter can be selected to assess which substrate is suitable for cell imaging.

Therefore, a multivariate approach was necessary, considering many parameters at the same time for a correlation with spectral data. The principal component regression (PCR) approach can be used to calibrate multivariate objects and thus compare systems defined by several parameters. Fig. 1A and B shows the main results obtained with PCR for spectral data obtained at nucleus location on cell FTIR images. At the nucleus location,
TABLE II

Correlation matrix between optical properties of substrates and spectral integration values at the nucleus location. fac - fatty acyl chains

\begin{tabular}{c|c|c|c|c|c|c}
\hline \hline & $n$ & $k$ & $A$ & $\tau$ & $b$ & $a$ \\
\hline amides & 0.186 & -0.427 & -0.487 & -0.789 & -0.507 & 0.383 \\
amide 1 & 0.291 & -0.404 & -0.407 & -0.780 & -0.512 & 0.425 \\
amide 2 & 0.402 & -0.343 & -0.456 & -0.769 & -0.482 & 0.503 \\
fac & 0.616 & -0.233 & -0.423 & -0.339 & -0.314 & 0.407
\end{tabular}

TABLE III

Significant parameters from the PCR test between optical and biological properties of substrates and spectral data at nucleus location of cells.

\begin{tabular}{c|c|c|c|c|c|c|c}
\hline \hline & $R^{2}$ & $n$ & $k$ & $A$ & $\tau$ & $b$ & $a$ \\
\hline amides & 0.815 & 0.354 & & & -0.597 & -0.454 & 0.439 \\
amide 1 & 0.845 & 0.464 & -0.659 & & -0.559 & -0.474 & 0.346 \\
amide 2 & 0.845 & 0.508 & & -0.753 & & & \\
fac & 0.698 & 0.675 & & -0.533 & & &
\end{tabular}

i.e., where the largest part of the signal comes from the nucleus itself (dense proteic object), but also from cytoskeleton (dense around nucleus for stability purposes), it was found that refractive index, adhesion, contact angle, and biotoxicity are the most significant parameters. Indeed, Fig. 1A points out the correlation between the parameters and two factors (F1, F2). Again, considering the results shown in Fig. 1B, the adhesion parameter is the most relevant. This bi-plot shows that diamond, GLS, $\mathrm{ZnS} / \mathrm{F}$ and $\mathrm{PbF}_{2}$ are in opposite position with adhesion parameter, and then unsuitable for cell growth. If diamond is characterized by a poor adhesiveness, $\mathrm{PbF}_{2}$, 
GLS, and ZNS/F are characterized by a high toxicity (see Table I). In addition PCR gives the value of each parameter with their standard deviation and the value of the $t$-student test. A variable is significant when the $p$ value greater than $|t|$ is less than $0.01 \%$. Thus, Table III shows only the significant parameters. Consequently, to have the highest integration value i.e., for example the highest SNR value for the amide I region, we need a substrate with high adhesion level, high refractive index, low biotoxicity, low contact angle, and low thermal conductivity. Physical parameters of substrates involved in multivariate correlation with IR signal level were found more numerous for amides absorption (1700-1480 $\left.\mathrm{cm}^{-1}\right)$, with a higher correlation coefficient $(>0.8)$, than for fatty acyl chains absorptions $\left(3020-2800 \mathrm{~cm}^{-1}\right)$. This is due to the higher SNR found in the amide spectral region, where the signal is by far higher than in the fatty acyl chains range. With an IR microscopy setup providing a $1.1 \times 1.1 \mu \mathrm{m}^{2}$ pixel resolution, this is clearly a direct consequence of the low organic material found at the single cell level [13]. Therefore, one must consider that correlations emerging by this cell imaging study among substrates physical properties and IR absorption values are more reliable for the amide spectral range. The most suitable substrates characterized by the highest adhesiveness and refractive index values are $\mathrm{Si}>\mathrm{Ge}>\mathrm{Si}_{3} \mathrm{~N}_{4}>\mathrm{LaF}_{3}>\mathrm{ZnS} / \mathrm{C}$. Moreover, considering the biocompatibility results obtained, $\mathrm{Ge}, \mathrm{Si}, \mathrm{Si}_{3} \mathrm{~N}_{4}$, and $\mathrm{LaF}_{3}$ are the best substrates for cell cultures devoted to high quality FTIR imaging.

\section{Conclusion}

The aim of this study was to determine the best substrate allowing to achieve the highest SNR for FTIR cell imaging. An important result we obtained was the poor biocompatibility of several substrates commonly used by IR spectroscopists such as for $\mathrm{CaF}_{2}$ or $\mathrm{ZnSe}$. The latter do not appear suitable for IR imaging of cultured cell, a prerequisite condition for live cell analyses. Optical properties of biocompatible substrates were further tested. Data point out that best substrates for FTIR imaging are Si and Ge. Germanium is already used in commercial ATR crystals and can be then reasonably considered a suitable material for high-quality high-resolution live cell imaging by means of FTIR microscopy. This study also points out that a rationale selection of substrates for live cell IR imaging have to be considered to push the IR spectroscopy towards in vitro applications.

\section{Acknowledgments}

The authors are indebted to the "Ligue Contre le Cancer", the "Agence Nationale pour la Recherche - ANR" for their financial supports, and the European Community's Seventh Framework Programme (FP7/2007-2013) under the grant agreement no. 226716.

\section{References}

[1] C. Petibois, Anal. Bioanal. Chem. 397, 2031 (2010).

[2] A. Marcelli, A. Cricenti, W.M. Kwiatek, C. Petibois, Biotechnol. Adv. 30, 1390 (2012).
[3] N. Blow, Nature 456, 825 (2008).

[4] F.L. Martin, J.G. Kelly, V. Llabjani, P.L. MartinHirsch, I.I. Patel, J. Trevisan, N.J. Fullwood, M.J. Walsh, Nat. Protoc. 5, 1748 (2010).

[5] S.W. Hell, Science 316, 1153 (2007).

[6] Z. Liu, X. Li, S.M. Tabakman, K. Jiang, S. Fan, H. Dai, J. Am. Chem. Soc. 130, 13540 (2008).

[7] S. Yao, H.H. Chen, E. Harte, G.D. Ventura, C. Petibois, Anal. Bioanal. Chem. 405, 8737 (2013).

[8] C. Petibois, M. Cestelli Guidi, Anal. Bioanal. Chem. 391, 1599 (2008).

[9] C. Petibois, B. Desbat, Trends Biotechnol. 28, 495 (2010).

[10] C. Petibois, G. Déléris, Trends Biotechnol. 24, 455 (2006).

[11] C. Petibois, M. Cestelli Guidi, M. Piccinini, M. Moenner, A. Marcelli, Anal. Bioanal. Chem. 397, 2123 (2010).

[12] B. Drogat, M. Bouchecareilh, C. Petibois, G. Déléris, E. Chevet, A. Bikfalvi, M. Moenner, J. Cell. Physiol. 212, 463 (2007).

[13] C. Petibois, G. Cazorla, H. Gin, G. Deleris, J. Lab. Clin. Med. 137, 184 (2001).

[14] C. Petibois, G. Deleris, M. Piccinini, M. Cestelli Guidi, A. Marcelli, Nat. Photon. 3, 179 (2009).

[15] M. Cestelli Guidi, S. Yao, D. Sali, S. Castano, A. Marcelli, C. Petibois, Biotechnol. Adv. 31, 402 (2013).

[16] N. Jamin, P. Dumas, J. Moncuit, W.H. Fridman, J.L. Teillaud, G.L. Carr, G.P. Williams, Proc. Natl. Acad. Sci. USA 95, 4837 (1998).

[17] K. Wehbe, J. Filik, M.D. Frogley, G. Cinque, Anal. Bioanal. Chem. 405, 1311 (2013).

[18] C. Petibois, M. Piccinini, M. Cestelli-Guidi, A. Marcelli, J. Synchrotron Rad. 17, 1 (2010).

[19] P. Innocenzi, T. Kidchob, J.M. Bertolo, M. Piccinini, M.C. Guidi, C. Marcelli, J. Phys. Chem. B Condens Matter. Mater. Surf. Interfaces Biophys. 110, 10837 (2006).

[20] M. Diem, M. Romeo, S. Boydston-White, M. Miljkovic, C. Matthäus, Analyst 129, 880 (2004).

[21] H.Y. Holman, R. Miles, Z. Hao, E. Wozei, L.M. Anderson, H. Yang, Anal. Chem. 81, 8564 (2009).

[22] H.-Y.N. Holman, M.C. Martin, E.A. Blakely, K. Bjornstad, W.R. Mckinney, Biopolymers 57, 329 (2000).

[23] J. Kneipp, L.M. Miller, S. Spassov, F. Sokolowski, P. Lasch, M. Beekes, D. Naumann, Biopolymers 74, 163 (2004).

[24] C. Paluszkiewicz, W.M. Kwiatek, A. Banas, A. Kisiel, A. Marcelli, M. Piccinini, Vib. Spectrosc. 43, 237 (2007).

[25] B.R. Wood, M.A. Quinn, B. Tait, M. Ashdown, T. Hislop, M. Romeo, D. McNaughton, Biospectroscopy 4, 75 (1998).

[26] C. Petibois, A. Cassaigne, H. Gin, G. Deleris, J. Clin. Endocrinol. Metab. 89, 3377 (2004). 